\title{
Thermal properties of ruthenium alkylidene-polymerized dicyclopentadiene
}

\author{
Yuval Vidavsky ${ }^{1}$, Yotam Navon ${ }^{2}$, Yakov Ginzburg ${ }^{1}$, Moshe Gottlieb ${ }^{2}$ \\ and N. Gabriel Lemcoff ${ }^{* 1}$
}

\author{
Full Research Paper \\ Address: \\ ${ }^{1}$ Department of Chemistry, Ben-Gurion University of the Negev Beer \\ Sheva-84105, Israel and ${ }^{2}$ Department of Chemical Engineering, \\ Ben-Gurion University of the Negev Beer Sheva-84105, Israel \\ Email: \\ N. Gabriel Lemcoff* - lemcoff@bgu.ac.il \\ * Corresponding author \\ Keywords: \\ glass-transition temperature; polydicyclopentadiene; ring opening \\ metathesis polymerization; ruthenium-catalyzed olefin metathesis; \\ thermoset polymers
}

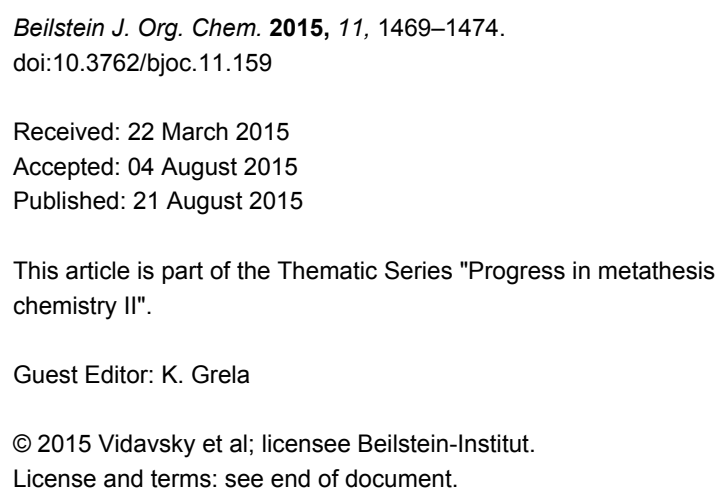

\begin{abstract}
Differential scanning calorimetry (DSC) analysis of ring opening methatesis polymerization (ROMP) derived polydicyclopentadiene (PDCPD) revealed an unexpected thermal behavior. A recurring exothermic signal can be observed in the DSC analysis after an elapsed time period. This exothermic signal was found to be proportional to the resting period and was accompanied by a constant increase in the glass-transition temperature. We hypothesize that a relaxation mechanism within the cross-linked scaffold, together with a long-lived stable ruthenium alkylidene species are responsible for the observed phenomenon.
\end{abstract}

\section{Introduction}

Olefin metathesis [1-6] has advanced to become a major synthetic tool in academia [7-11] and industry [12]. Metathesis polymerization techniques [13-15], and especially ring opening metathesis polymerization (ROMP) [16,17], have had a vital role in this growth. Polydicyclopentadiene (PDCPD), probably the most widely used metathesis polymer, is formed through ROMP of mostly endo-dicyclopentadiene (DCPD, 1) (Figure 1). The Grubbs-type ruthenium initiators, known for their high activity, stability and functional group tolerance are extensively used to promote this type of olefin metathesis reactions. For example, the Grubbs second generation catalyst 2 [18] (Figure 1), may be used to initiate ROMP reactions of suitable strained cycloolefins.

DCPD is a common byproduct in the naphtha cracking process [19] and has two carbon-carbon double bonds, which readily 


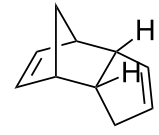

1

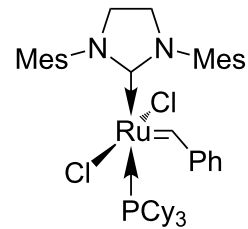

2
Figure 1: DCPD (1) and ruthenium benzylidene catalyst 2.

undergo ROMP reactions with ruthenium alkylidenes. By adding the appropriate initiator, the highly strained and reactive norbornene double bond can be disrupted first to afford a linear polymer, followed by the ring opening of the less reactive cyclopentene double bond to effectively cross-link the chains (Scheme 1). Notably, with tungsten and molybdenum initiators the linear polymer may be isolated [20,21]; unlike the case with ruthenium initiators where only cross-linked polymers are obtained. This polyolefinic cross-linked thermoset material exhibits outstanding thermal stability [22], mechanical strength [23], fracture toughness [24] and dielectric characteristics [25] Thanks to these properties PDCPD has become a very attractive polymer for several applications and is one of the most ubiquitous ROMP materials in industrial uses.
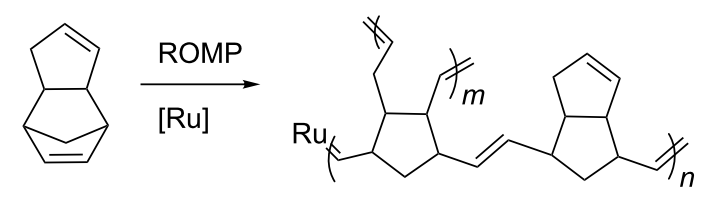

Scheme 1: ROMP of dicyclopentadiene by a ruthenium alkylidene initiator.

The relatively new PDCPD polymer has been widely explored for its thermal properties over the past decade. Cao et al. [26] reported glass-transition temperatures $\left(T_{\mathrm{g}}\right)$ as high as $165^{\circ} \mathrm{C}$ and total conversions of $98.9 \%$ at polymerization temperatures of $60{ }^{\circ} \mathrm{C}$ with the Grubbs first generation catalyst. By carrying out detailed differential scanning calorimetry (DSC) analyses Kessler and Mauldin [27] demonstrated a sharp exothermic peak related to the heat of reaction and a final $T_{\mathrm{g}}$ of $164{ }^{\circ} \mathrm{C}$ at conversions of $90 \%$ right after curing. Dimonie et al. [28,29] examined the nature of the first exothermic peak of linear PDCPD using DSC and showed thermal polymerization completion after $2 \mathrm{~h}$ at $150{ }^{\circ} \mathrm{C}$ as the exothermic peak disappeared given these conditions. Kessler and White [30] also explored the cure kinetics of the polymer using DSC and reached a $T_{\mathrm{g}}$ of $139^{\circ} \mathrm{C}$ for a "fully cured" product. In addition, Lee et al. [31] showed the absence of the exothermic peak on a second DSC scan, revealing a $T_{\mathrm{g}}$ as high as $160^{\circ} \mathrm{C}$. While literature glass-transition temperatures range from 140 to $165^{\circ} \mathrm{C}$, the polymer's thermal behavior for extended periods of time is not usually reported. Understanding this behavior is crucial for a polymer with a wide range of engineering applications in order to ensure the effectiveness and long-standing stability of the polymer. In this work we examined the thermal behavior over time of PDCPD obtained by ruthenium-induced ROMP of DCPD.

\section{Results and Discussion}

The observation of recurrent exothermic peaks in calorimetric analyses and a continuous rise in glass-transition temperature over time led us to study this phenomenon and propose a plausible mechanism for this behavior.

When a sample of PDCPD produced by ROMP of DCPD with catalyst 2 was initially subjected to a differential scanning calorimeter (DSC) run cycle, a strong exothermic peak was observed, which was at first associated with the reaction of remaining DCPD according to previous studies. Fourteen further DSC cycles were run immediately and, as expected, no exothermic peak was observed (Figure 2, top). The glass-transition temperature $\left(T_{\mathrm{g}}\right)$ signature was observed at $148{ }^{\circ} \mathrm{C}$, with good correlation to literature values (vide supra).

As stated before, we desired to monitor the $T_{\mathrm{g}}$ over time; thus, the same sample was subjected to an additional identical DSC cycle two weeks later. To our surprise, an exothermic peak reappeared and the $T_{\mathrm{g}}$ value was recorded at $162.6^{\circ} \mathrm{C}$ (Figure 2, bottom). Carrying out the measurement and the subsequent storage under nitrogen atmosphere afforded the same results. DSC analyses were then repeated with a number of polymer samples and the 'return' of the exothermic peak after prolonged time periods was found to be completely reproducible, a finding which led us to further investigate this phenomenon.

Thus, a set of PDCPD samples was subjected to a series of DSC heating-cooling cycles, with resting periods at room temperature between the cycles. During a period of 120 days the $T_{\mathrm{g}}$ constantly increased with every rest period until its value could not be further detected by the DSC analysis. A maximum glasstransition temperature was recorded at approximately $210{ }^{\circ} \mathrm{C}$, which is to our knowledge the highest $T_{\mathrm{g}}$ recorded for PDCPD in the scientific literature (Figure 3).

The rise of the $T_{\mathrm{g}}$ after the rest periods was permanently accompanied by the reappearance of the exothermic peak. It was furthermore observed that the sample with the longest rest period of 16 months at room temperature showed the largest exothermic peak. The intensity of the exothermic peak was 

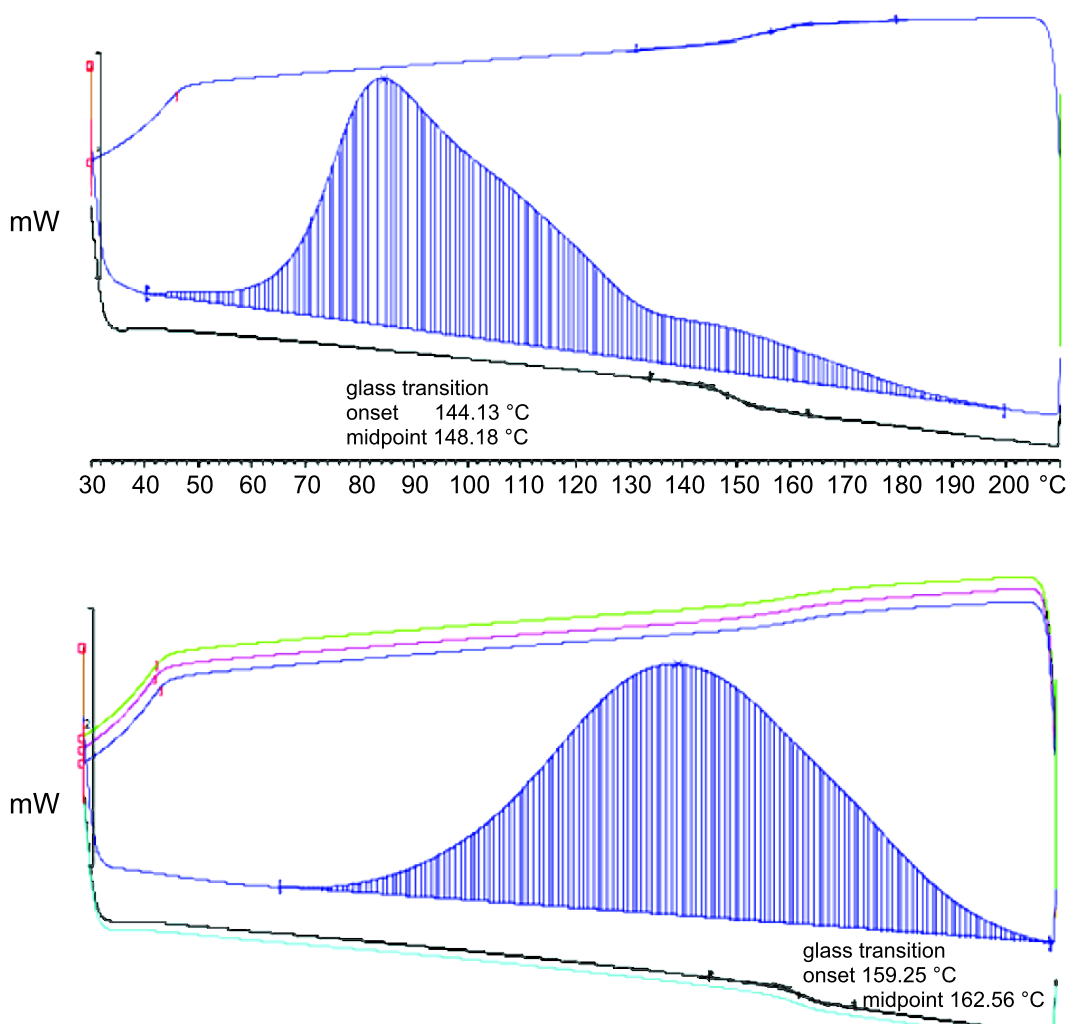

$304050 \quad 60 \quad 70 \quad 80 \quad 90 \quad 100110120130140150160170180190200{ }^{\circ} \mathrm{C}$

Figure 2: Top: DSC plot of PDCPD 24 hours after polymerization. Blue line: 1st heating-cooling cycle. Black line: 2nd cycle. Bottom: DSC of PDCPD sample after two weeks. Blue line shows the reappearing exothermic peak (1st cycle). The black and cyan lines show the elevation in $T_{\mathrm{g}}$ and disappearance of the exothermic peak.

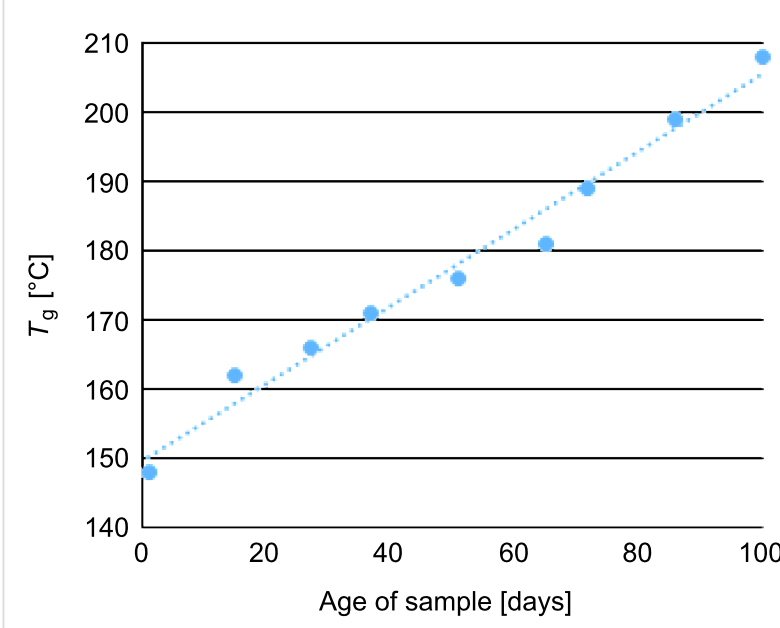

Figure 3: Change in $T_{\mathrm{g}}$ for a representative PDCPD sample as a function of time.

strongly correlated to the rest time between the analyses, where longer resting periods gave larger exothermic peaks (Figure 4) and very short time periods (such as the immediate repetition) did not afford any exothermic signal at all. For instance, a sample that was rested for 16 months without heating showed an extremely strong exothermic peak with a value of $151 \mathrm{~J} / \mathrm{g}$, even larger than the peaks observed at the first measurement.

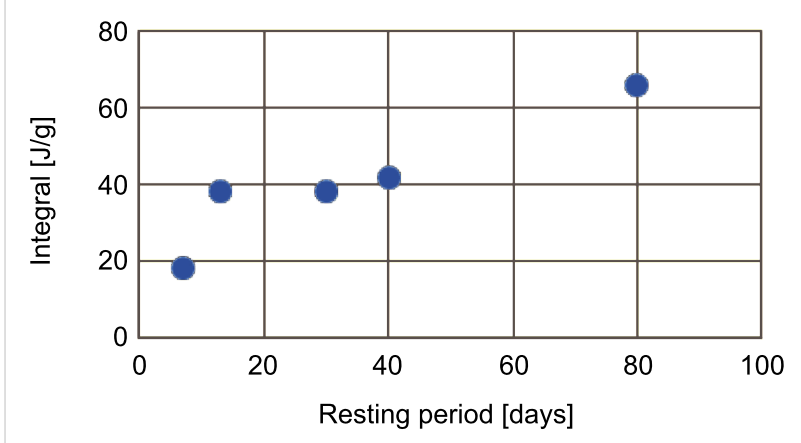

Figure 4: Intensity of exothermic peak as a function of rest time at room temperature for different samples.

A sample that was allowed equal rest periods of two weeks (Figure 5) showed very similar exothermic integrals (ca. 
$40 \mathrm{~J} / \mathrm{g}$ ), even after 90 days, except for the first two abnormally high peaks (probably due to reaction of unreacted strained cycloalkenes in the sample).

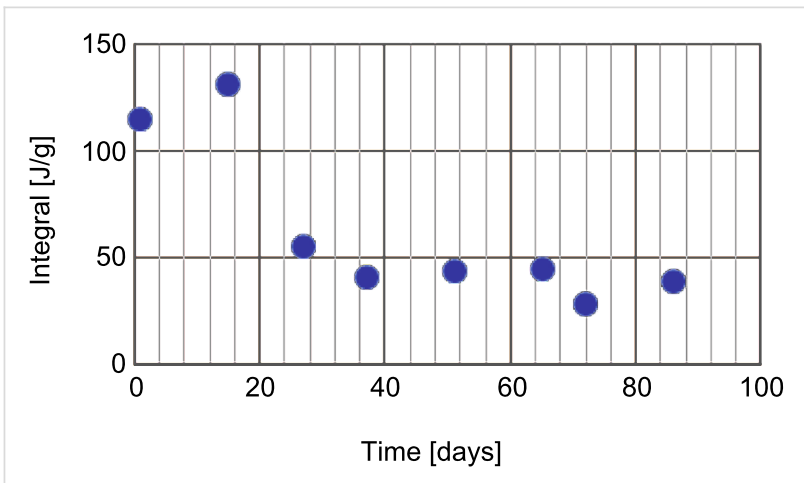

Figure 5: Peak intensity as function of age. Samples were analyzed every two weeks. The abnormal low intensity of the peak after 72 days is due to one week rest time instead of the regular two weeks rest time. The high intensity observed in the first two measurements may be attributable to further polymerization of unreacted cyclopentene bonds and free monomer.

It is important to note that the samples were always weighed between heating cycles and the weight of the crucible and polymer remained unchanged throughout the experiment. As the effect of resting time was established, we proceeded to study whether the resting temperature would influence the observed exothermic signal and the resultant $T_{\mathrm{g}}$. Therefore, a set of samples was prepared, similar DSC cycles were run but this time, the samples were rested at different temperatures, i.e., room temperature, $-5{ }^{\circ} \mathrm{C}$, and at $-196^{\circ} \mathrm{C}$ (liquid nitrogen).

As shown in Figure 6, only extreme cooling using liquid nitrogen reduced the peak intensity significantly by $63 \%$, compared to ambient temperature. Storage of the sample at $-5{ }^{\circ} \mathrm{C}$ still afforded a relatively strong exothermic signal.

According to the ROMP mechanism, a ruthenium alkylidene species may remain entrapped within the PDCPD matrix. The data collected led us to assume that the exothermic peak may arise from an internal metathetic process which occurs only after the polymer microstructure equilibrates and further ruthenium-alkylidene metathesis with neighboring double bonds may be promoted. Alternatively, thermal decomposition of DCPD (or larger oligomers) to cyclopentadiene (CPD) by a retro-Diels-Alder reaction could also explain the observed phenomenon, although unlikely at room temperature. Both hypotheses were tested.

CPD is less reactive in metathesis reactions than DCPD, and will gradually dimerize at ambient conditions to give the latter. In order to estimate a possible formation of $\mathrm{CPD}$ as the reason

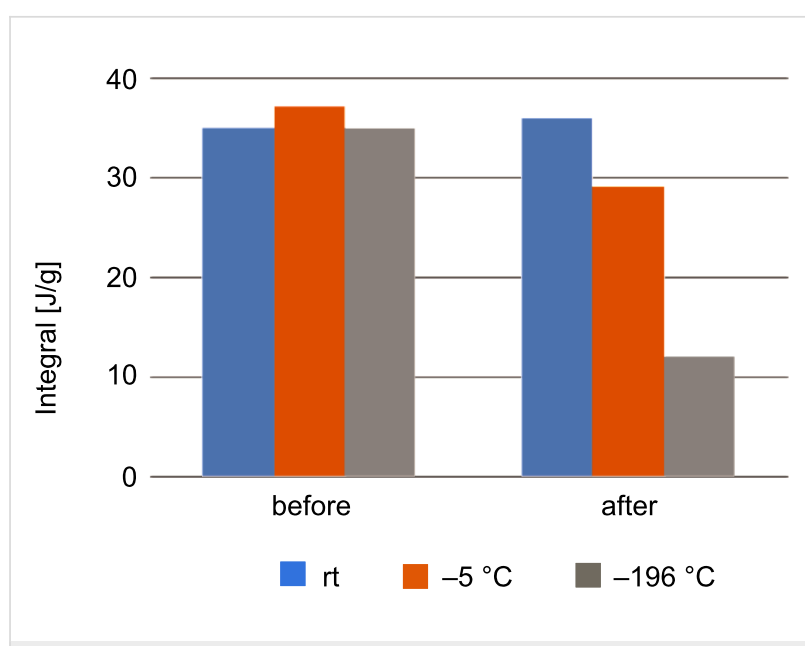

Figure 6: Resting temperature effect. Blue columns: resting at room temperature. Orange columns: resting at $-5{ }^{\circ} \mathrm{C}$. Gray columns: resting at $-196^{\circ} \mathrm{C}$. Time elapsed between measurements was 1 week.

for the observed thermal behavior, a series of DCPD samples with different percentages of externally added CPD were subjected to heat-cool-rest cycles. Table 1 shows the lack of correlation between the amount of CPD in the sample and the glass-transition temperature increase. Moreover, the presence of volatile monomers such as DCPD and, even more so CPD, after heating cycles and long periods of time is highly improbable.

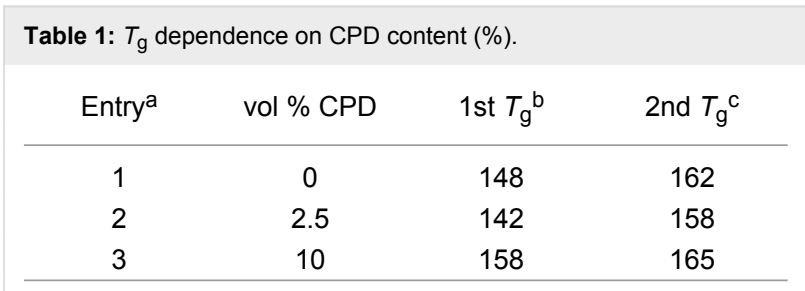

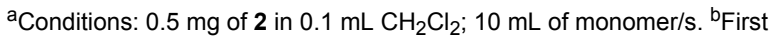
DSC run after 24 hours at $60^{\circ} \mathrm{C}$. ' $\mathrm{Second}$ DSC run after two weeks at room temperature.

As mentioned before, we hypothesized that the exothermic signal reemerged due to secondary metathesis reactions which can occur after polymer relaxation and repositioning of the active ruthenium alkylidene within the cross-linked polymer network. To validate this assumption a sample in the DSC crucible was flooded with ethyl vinyl ether for 5 days, trying to deactivate any remaining catalytic species by formation of inert Fischer carbene [32]. A control sample was flooded with diethyl ether. To our satisfaction, in the sample treated with ethyl vinyl ether the exothermic peak was suppressed while the control experiment (with diethyl ether) behaved as indicated in previous experiments (Figure 7). These results support the theory that an olefin metathesis reaction is occurring and that it is the source of the observed exothermic peak. 

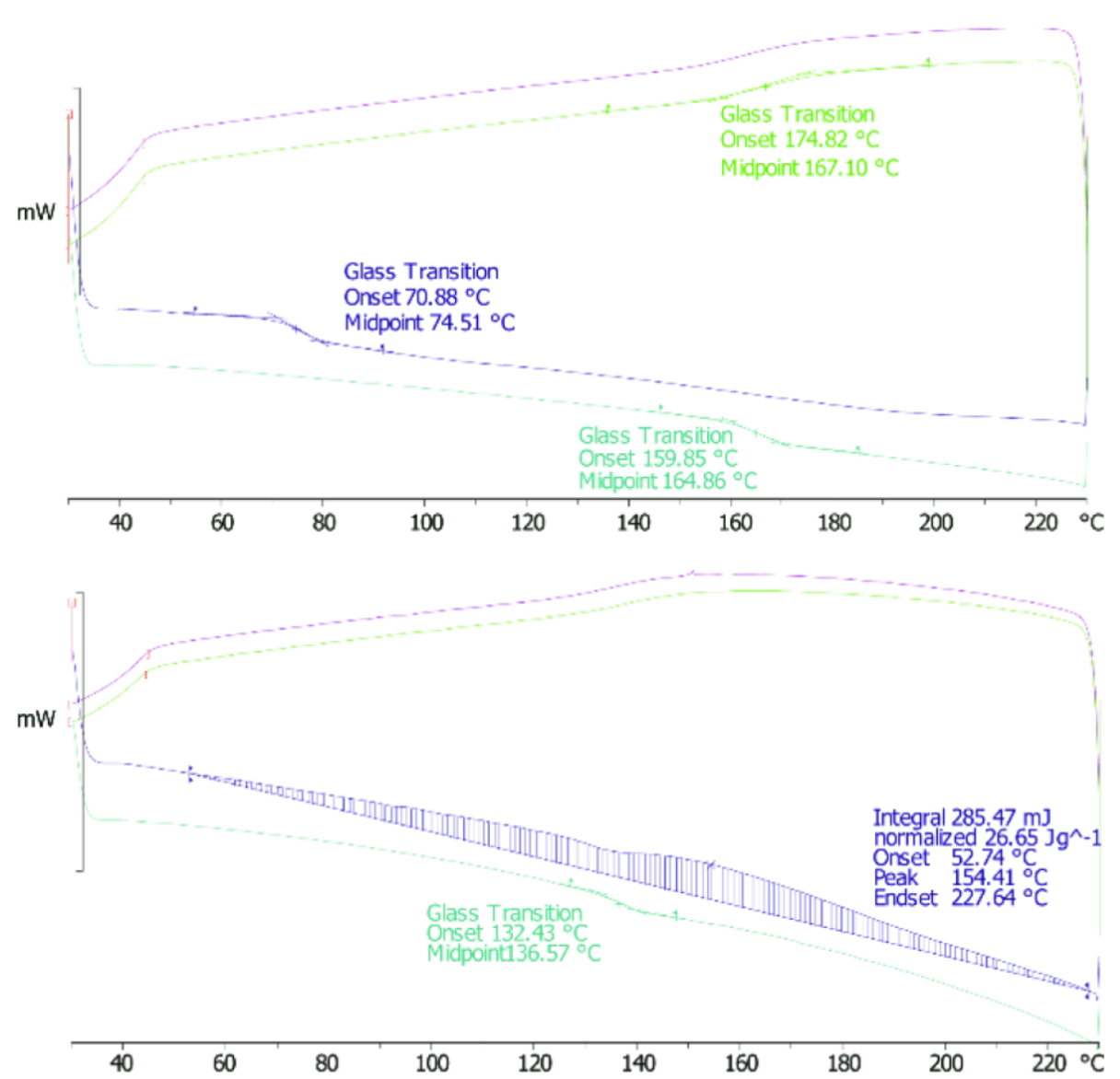

Figure 7: Top: Sample after 1 week with ethyl vinyl ether. Bottom: Sample after 1 week with diethyl ether.

\section{Conclusion}

In summary, the ruthenium-catalyzed DCPD polymerization produced a polymer with an unexpected thermal behavior over long periods of time. The DSC analysis after polymerization showed a large exothermic peak, which was initially assigned to exothermicity of ROMP of unreacted cycloalkane. However, this peak reappeared repeatedly after defined resting periods (days-weeks). Our study suggests that a relaxation process is occurring within the polymer and that a long-lived catalytic species inside the polymer may still be active after prolonged periods of time. Additionally, we showed that by repeating the heating-cooling cycles over time an unprecedented glass-transition temperature for PDCPD of $210^{\circ} \mathrm{C}$ was obtained. This is to the best of our knowledge the highest $T_{\mathrm{g}}$ for PDCPD recorded so far. Ongoing efforts in the lab are geared towards further elucidating the mechanism and possible applications of these observations.

\section{Experimental}

All commercially available chemicals were of reagent grade quality and used without further purification, unless described.
Differential scanning calorimetry (DSC) data was obtained using a METTLER-TOLEDO DSC 823 and results were evaluated with the STARe software. All experiments were performed with a nitrogen flow of $80 \mathrm{~mL} / \mathrm{min}$ at a heating rate of $5{ }^{\circ} \mathrm{C} / \mathrm{min}$. Each sample was subjected to $2-3$ heating-cooling cycles.

\section{Polymerization procedures}

endo-Dicyclopentadiene $(10 \mathrm{~mL}, 74 \mathrm{mmol})$ and a stirring magnet were added to a $20 \mathrm{~mL}$ vial and kept at $40{ }^{\circ} \mathrm{C}$ in order to melt the monomer. In a separate $2 \mathrm{~mL}$ vial, initiator $2(0.5 \mathrm{mg}$, $\left.5.9 \times 10^{-4} \mathrm{mmol}\right)$ was dissolved in dichloromethane $(100 \mu \mathrm{L})$. The dissolved initiator was then transferred by syringe to the vial containing the monomer upon vigorous stirring and a $10-15 \mu \mathrm{L}$ sample was immediately placed in a DSC $40 \mu \mathrm{L}$ aluminum crucible. Because the monomer mixture solidifies as it comes into contact with the crucible, the latter was warmed up to $40^{\circ} \mathrm{C}$ to ensure a uniform coverage on the surface of the crucible. The crucible was then sealed with an aluminum cap, and stored at $60{ }^{\circ} \mathrm{C}$ for 24 hours for complete curing of the PDCPD. During resting periods the crucible was stored at room temperature under ambient conditions unless otherwise noted. 


\section{Acknowledgements}

The Israel Science Foundation is gratefully acknowledged for partial financial support.

\section{References}

1. Vougioukalakis, G. C.; Grubbs, R. H. Chem. Rev. 2010, 110, 1746-1787. doi:10.1021/cr9002424

2. Samojłowicz, C.; Bieniek, M.; Grela, K. Chem. Rev. 2009, 109, 3708-3742. doi:10.1021/cr800524f

3. Boeda, F.; Clavier, H.; Nolan, S. P. Chem. Commun. 2008, 2726-2740. doi:10.1039/b718287b

4. Diesendruck, C. E.; Tzur, E.; Lemcoff, N. G. Eur. J. Inorg. Chem. 2009, 28, 4185-4203. doi:10.1002/ejic.200900526

5. Monfette, S.; Fogg, D. E. Chem. Rev. 2009, 109, 3783-3816. doi:10.1021/cr800541y

6. Dunbar, M. A.; Balof, S. L.; LaBeaud, L. J.; Yu, B.; Lowe, A. B.; Valente, E. J.; Schanz, H.-J. Chem. - Eur. J. 2009, 15, 12435-12446. doi:10.1002/chem.200901013

7. Nicolaou, K. C.; Bulger, P. G.; Sarlah, D. Angew. Chem., Int. Ed. 2005, 44, 4490-4527. doi:10.1002/anie.200500369

8. Connon, S. J.; Blechert, S. Angew. Chem., Int. Ed. 2003, 42, 1900-1923. doi:10.1002/anie.200200556

9. Grubbs, R. H., Ed. Handbook of Metathesis: Catalyst Development; Wiley-VCH Verlag GmbH: Weinheim, 2008.

10. Giudici, R. E.; Hoveyda, A. H. J. Am. Chem. Soc. 2007, 129, 3824-3825. doi:10.1021/ja070187v

11. Michrowska, A.; Gułajski, L.; Kaczmarska, Z.; Mennecke, K.; Kirschning, A.; Grela, K. Green Chem. 2006, 8, 685-688. doi:10.1039/b605138c

12. Mol, J. C. J. Mol. Catal. A: Chem. 2004, 213, 39-45. doi:10.1016/j.molcata.2003.10.049

13. Bielawski, C. W.; Benitez, D.; Grubbs, R. H. Science 2002, 297 , 2041-2044. doi:10.1126/science.1075401

14. Schwendeman, J. E.; Church, A. C.; Wagener, K. B. Adv. Synth. Catal. 2002, 344, 597-613.

15. Burtscher, D.; Lexer, C.; Mereiter, K.; Winde, R.; Karch, R.; Slugovc, C. J. Polym. Sci., Part A-1: Polym. Chem. 2008, 46, 4630-4635. doi:10.1002/pola.22763

16. Ivin, K. J.; Mol, J. C. Olefin Metathesis and Metathesis Polymerization; Academic Press: San Diego, 1997.

17. Sutthasupa, S.; Shiotsuki, M.; Sanda, F. Polym. J. 2010, 42, 905-915. doi:10.1038/pj.2010.94

18. Schwab, P.; Grubbs, R. H.; Ziller, J. W. J. Am. Chem. Soc. 1996, 118, 100-110. doi:10.1021/ja952676d

19. Johnson, H. F. Cyclopentadiene. U.S. Patent 2,636,054, April 21, 1953.

20. Davidson, T. A.; Wagener, K. B. J. Mol. Catal. A: Chem. 1998, 133, 67-74. doi:10.1016/S1381-1169(98)00091-0

21. Dragutan, V.; Demonceau, A.; Dragutan, I.; Finkelshtein, E. S., Eds. Green Metathesis Chemistry; Springer: Dordrecht, 2010. doi:10.1007/978-90-481-3433-5

22. Mühlebach, A.; van der Schaaf, P. A.; Hafner, A.; Setiabudi, F. J. Mol. Catal. A: Chem. 1998, 132, 181-188. doi:10.1016/S1381-1169(97)00241-0

23. Hine, P. J.; Leejarkpai, T.; Khosravi, E.; Duckett, R. A.; Feast, W. J. Polymer 2001, 42, 9413-9422. doi:10.1016/S0032-3861(01)00488-8

24. Jeong, W.; Kessler, M. R. Chem. Mater. 2008, 20, 7060-7068. doi:10.1021/cm8020947
25. Yin, W.; Kniajanski, S.; Amm, B. Dielectric properties of polydicyclopentadiene and polydicyclopentadiene-silica nanocomposite. In Conference Record of the IEEE International Symposium on Electrical Insulation, San Diego, CA, June 6-9, 2010; IEEE, 2010. doi:10.1109/ELINSL.2010.5549749

26. Yao, Z.; Zhou, L.; Dai, B.; Cao, K. J. Appl. Polym. Sci. 2012, 125, 2489-2493. doi:10.1002/app.36359

27. Mauldin, T. C.; Kessler, M. R. J. Therm. Anal. Calorim. 2009, 96, 705-713. doi:10.1007/s10973-009-0039-y

28. Dimonie, D.; Dimonie, M.; Munteanu, V.; lovu, H.; Couve, J.; Abadie, M. J. Polym. Degrad. Stab. 2000, 70, 319-324. doi:10.1016/S0141-3910(00)00093-8

29. Dimonie, D.; Dimonie, M.; Stoica, S.; Munteanu, V.; Abadie, M. J. Polym. Degrad. Stab. 2000, 67, 167-170. doi:10.1016/S0141-3910(99)00108-1

30. Kessler, M. R.; White, S. R. J. Polym. Sci. 2002, 40, 2373-2383. doi:10.1002/pola.10317

31. Lee, J. K.; Liu, X.; Ho Yoon, S.; Kessler, M. R. J. Polym. Sci. 2007, 45, 1771-1780. doi:10.1002/polb.21089

32. Wu, Z.; Nguyen, S. T.; Grubbs, R. H.; Ziller, J. W. J. Am. Chem. Soc. 1995, 117, 5503-5511. doi:10.1021/ja00125a010

\section{License and Terms}

This is an Open Access article under the terms of the Creative Commons Attribution License (http://creativecommons.org/licenses/by/2.0), which permits unrestricted use, distribution, and reproduction in any medium, provided the original work is properly cited.

The license is subject to the Beilstein Journal of Organic Chemistry terms and conditions:

(http://www.beilstein-journals.org/bjoc)

The definitive version of this article is the electronic one which can be found at: doi:10.3762/bjoc. 11.159 